\title{
Biochar loaded chitosan/gelatin/poly(ethylene glycol) biocomposite beads: Morphological, thermal and swelling properties
}

\section{Fatma Nur PARIN ${ }^{1}(\mathbb{D})$, Kenan YILDIRIM ${ }^{1,2^{*}}$ (D), Pınar TERZİOĞLU}

${ }^{I}$ Bursa Technical University, Faculty of Engineering and Natural Sciences, Department of Polymer Materials Engineering, Bursa, Turkey.

${ }^{2}$ Bursa Technical University, Central Research Laboratory, Bursa, Turkey

\begin{abstract}
Cite this paper as:
Parın, F.N., Yıldırım, K., Terzioğlu, P. (2020). Biochar loaded chitosan/gelatin/ poly(ethylene glycol) biocomposite beads: Morphological, thermal and swelling properties. Journal of Innovative Science and Engineering. 4(2): 56-68

*Corresponding author: Kenan YILDIRIM E-mail: kenan.yildirim@btu.edu.tr Tel: +90 (224) 3003557

Received Date: 28/05/2020 Accepted Date: 01/07/2020 (C) Copyright 2020 by Bursa Technical University. Available online at http://jise.btu.edu.tr/
\end{abstract}

\section{cc) (i) (s)}

The works published in Journal of Innovative Science and Engineering (JISE) are licensed under a Creative Commons Attribution-NonCommercial 4.0 International License.

\begin{abstract}
The chitosan/gelatin/biochar biocomposite beads were prepared via the use of the emulsion crosslinking method in the presence of poly(ethylene) glycol as a crosslinker. The effects of different ratios of biochar (1 and 5\%) on the characteristics of the beads were evaluated by scanning electron microscopy (SEM) and energydispersive X-ray spectroscopy (EDS), thermogravimetric analysis (TGA) and Attenuated Total Reflectance-Fourier Transform Infrared Spectroscopy (ATR-FTIR) and swelling studies. The FT-IR results showed the interactions of biochar and polymer matrix. The prepared beads showed good swelling properties and different morphologies. The average diameter of neat chitosan/gelatin beads was almost 725 $\mu \mathrm{m}$, while the average diameter of $1 \%$ and $5 \%$ biochar incorporated beads were 726 $\mu \mathrm{m}$ and $597 \mu \mathrm{m}$, respectively. The swelling capacity of the beads was decreased from $4671 \%$ to $2092 \%$ when the biochar incorporation ratio increased from $1 \%$ to $5 \%$. This indicated that the preparation of beads with varying properties can be achieved by controlling the biochar amount. The beads may be evaluated in various applications as polymeric carrier systems and adsorbents.
\end{abstract}

Keywords: chitosan, gelatin, biochar, biocomposite beads. 


\section{Introduction}

Superabsorbent polymers (SAPs) are three-dimensional cross-linked structures (3D) which exhibit the ability to absorb and hold a significant fraction of liquid (>20\%) within their own weight [1]. The SAPs are defined as hydrogel [2,3]. Their large water content results in a level of flexibility the same as natural tissue [4]. Several polymers can be used to prepare 3D network such as natural polymers (e.g. alginate, carboxymethyl cellulose, cellulose, chitosan, gelatin, pectin, starch), synthetic polymers (polyacrylic acid, polymethacrylic acid, polyethylene glycol, polyvinyl alcohol) and also various acrylates [3,5]. The major mechanism of reversible swelling ability is based on chemical bonds and physical interactions.

Hydrogels are available in various forms such as film, fiber, membrane, monolith, and bead $[3,4]$. Hydrogel beads are the spherical particulate systems with sizes ranging from $50 \mathrm{~nm}$ to $2 \mathrm{~mm}$ [6]. They are used in various fields including tissue engineering, thermal energy storage, adsorbent, drug delivery, hygienic, agricultural, cosmetic, and food applications [7]. Chitosan is among the natural degradable polymers that can be used to prepare hydrogel beads. It is the second most abundant heteropolysaccharide, obtained by the partial deacetylation of chitin, which is composed of $\beta$-(14)-2-acetamido-2-deoxy- $\beta$-D-glucopyranose and 2-amino-2-deoxy- $\beta$-D-glucopyranose groups $[2,5,8]$. The chitosan beads gained increasing attention due to being biocompatible, biodegradable, and modifiable as well as having water holding capacity.

In recent years, composite beads have a worldwide focus to obtain novel desirable polymer materials for practical applications by improving the properties of neat beads $[9,10]$. Chitosan-gelatin blends have been reported to have enhanced mechanical properties [11] and good adsorption properties [12]. Gelatin is a high molecular weight polypeptide which is obtained by the partial hydrolysis of collagen [13]. Similar to chitosan, gelatin is biodegradable and biocompatible [14]. Withal, the common drawback of chitosan and gelatin is the weak stability in an aqueous environment [12].

To enhance stability as well as mechanical, thermal, and surface properties, various reinforcing fillers can be incorporated into beads. Carbon-based ones (e.g. active carbon, biochar, carbon nanotube, graphene etc.) are some of the most used fillers. Among these, biochar is seriously proposed owing to its unique properties including high porosity, chemical stability, and high adsorption capacity [15,16]. Additionally, it is cost-effective and widely available [17]. On the other hand, biochar can be used in environmental remediation and soil amendment applications. However, biochar particles are easily agglomerated in aqueous environments. Therefore, the preparation of a three-dimensional bead will enhance the adsorption capacity of both biochar and polymer matrix, and also simplify the separation of the adsorbent. The chitosan, gelatin, and biochar have their own favorable properties and combining them to obtain a composite hydrogel can get all their advantages. In view of these, it was considered favorable to incorporate biochar into chitosan/gelatin beads functionalized with poly (ethylene glycol). In this current study, chitosan/gelatin/biochar beads were synthesized by emulsion crosslinking method. PEG is used as a crosslinking agent. By varying the amount of reinforcement (biochar), the properties of the resulting beads were investigated in terms of chemical, morphological, thermal, and swelling properties. 


\section{Materials and Methods}

\subsection{Materials}

Chitosan $\left(\mathrm{C}_{6} \mathrm{H}_{11} \mathrm{NO}_{4}\right)_{\mathrm{n}}, 75-85 \%$ deacetylation, medium molecular weight) and glacial acetic acid $\left(\mathrm{CH}_{3} \mathrm{COOH}, 99 \%\right)$ and poly(ethylene) glycol (PEG, average Mn 400) were supplied from Sigma-Aldrich Chemical Company. Gelatin from bovine skin (220-230 Bloom, type B) was purchased from Bursa Jelatin Gida (Bursa, TURKEY). Biochar (particle size $<500 \mu \mathrm{m}$ ) was a kind gift from Synpet Technologies (Istanbul, TURKEY). Distilled water was used in the experiments and all of the reagents were used without any purification.

\subsection{Synthesis of Chitosan/Gelatin/Biochar Beads}

The biocomposite beads were prepared by modifying the method of $\mathrm{Wu}$ et al. Typically, chitosan powders $(1 \mathrm{~g})$ were dissolved in $40 \mathrm{~mL}$ of $2 \%(\mathrm{v} / \mathrm{v})$ acetic acid and then gelatin $(4 \mathrm{~g})$ and $10 \mathrm{~mL}$ distilled water was introduced to this solution with constant stirring at $500 \mathrm{rpm}$ for 16 hours at $40^{\circ} \mathrm{C}$. Subsequently, PEG-400 (1 g) was added to the solution and stirred at $250 \mathrm{rpm}$ for 2 hours at $40^{\circ} \mathrm{C}$. The beads were obtained by the dropwise addition of the solution using a plastic syringe $(10 \mathrm{~mL})$ into $200 \mathrm{~mL}$ of cold sunflower oil with continuous stirring. To achieve a complete gelation, the beakers containing the oil and beads were left in an ice-water mixture $\left(4^{\circ} \mathrm{C}\right)$. After 2 hours, the mixture was filtered. Finally, beads were washed with distilled water $(300 \mathrm{~mL})$ and distilled water:ethanol $(1: 1,100 \mathrm{~mL})$ solution. The beads were dried at room temperature for 2 days. Different compositions of chitosan-gelatin-biochar were prepared by varying the amount of biochar with $0 \%, 1 \%$, and $5 \%$ (wt $\%$ of total polymer), which were coded as Chi-Gel, Chi-Gel/BC1, and Chi-Gel/BC5, respectively. The experimental setup for the synthesis of the beads is shown in Figure1.
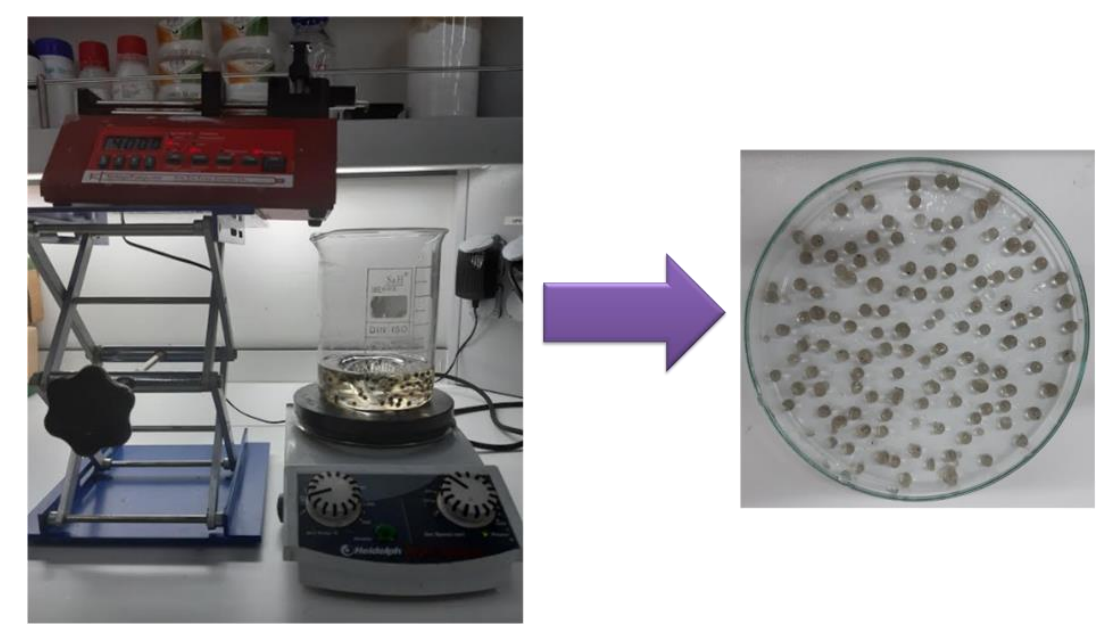

Figure 1. Digital photograph of preparation of chitosan/gelatin/biochar beads. 


\subsection{Characterization}

The morphology of all beads was observed using a scanning electron microscope (Carl Zeiss ${ }^{\mathrm{TM}}$ Gemini 300, Germany) and Leica M125 stereomicroscope. Samples were coated with gold and palladium using a vacuum evaporator and were examined at an accelerating voltage of $10 \mathrm{kV}$ before SEM analysis. Bead diameters/sizes were measured using Image $\mathrm{J}$ software (version 1.520j). The elemental analysis of beads was investigated by Energy-dispersive X-ray spectroscopy (EDS) by a Bruker XFlash ${ }^{\circledR} 6 \mid 100$ detector (Bruker QUANTAX, USA).

Thermogravimetric analyses (TGA) of the beads were performed using a TGA STA 6000 analyzer from Perkin Elmer ${ }^{\mathrm{TM}}$ Instruments (USA) to determine thermal stability. The samples were heated from $30^{\circ} \mathrm{C}$ to $600^{\circ} \mathrm{C}$ under a nitrogen atmosphere at a heating rate of $20^{\circ} \mathrm{C} / \mathrm{min}$ and applied oxygen atmosphere with $20^{\circ} \mathrm{C} \mathrm{min}^{-1}$ heating rate $600-900^{\circ} \mathrm{C}$ temperature. FTIR spectrum was obtained with a ThermoScientific ${ }^{\text {TM }}$ Nicolet iS50 FTIR (USA) with a Pike ATR (Attenuated Total Reflectance) adapter, in the range of $4000-500 \mathrm{~cm}^{-1}$ recorded with 16 scans at $4 \mathrm{~cm}^{-1}$ resolutions.

\subsection{Swelling Behaviour}

The swelling behaviours of the composite beads were determined by immersing in distilled water $(10 \mathrm{~mL})$ at room temperature $\left(25^{\circ} \mathrm{C}\right)$ until the swelling equilibrium was achieved [12]. After 6 hours, the swollen samples were separated and the excess surface water was gently removed by a filter paper. Then, the weight of beads was measured using a weighing balance. The swelling ratio was calculated by the following equation:

$$
\operatorname{Swelling}(\%)=\frac{m_{f}-m_{i}}{m_{i}} x 100
$$

where $m_{i}$ and $m_{f}$ are the weights of the initial bead and final wet bead, respectively.

\section{Results and Discussion}

\subsection{Morphology Analysis}

The surface morphologies of the prepared beads are shown in Figure 2. It can be seen that the beads have near-spherical shape and irregular surface texture. The biochar loaded samples (Figure 2.b-c) demonstrated relatively smoother surface than the neat bead (Figure 2.a). It can be related to the increased interactions between the functional groups of biochar and the polymer network. The EDS results showed that the carbon ratios of biochar incorporated beads were a little higher than the neat bead as expected (Table 1). 


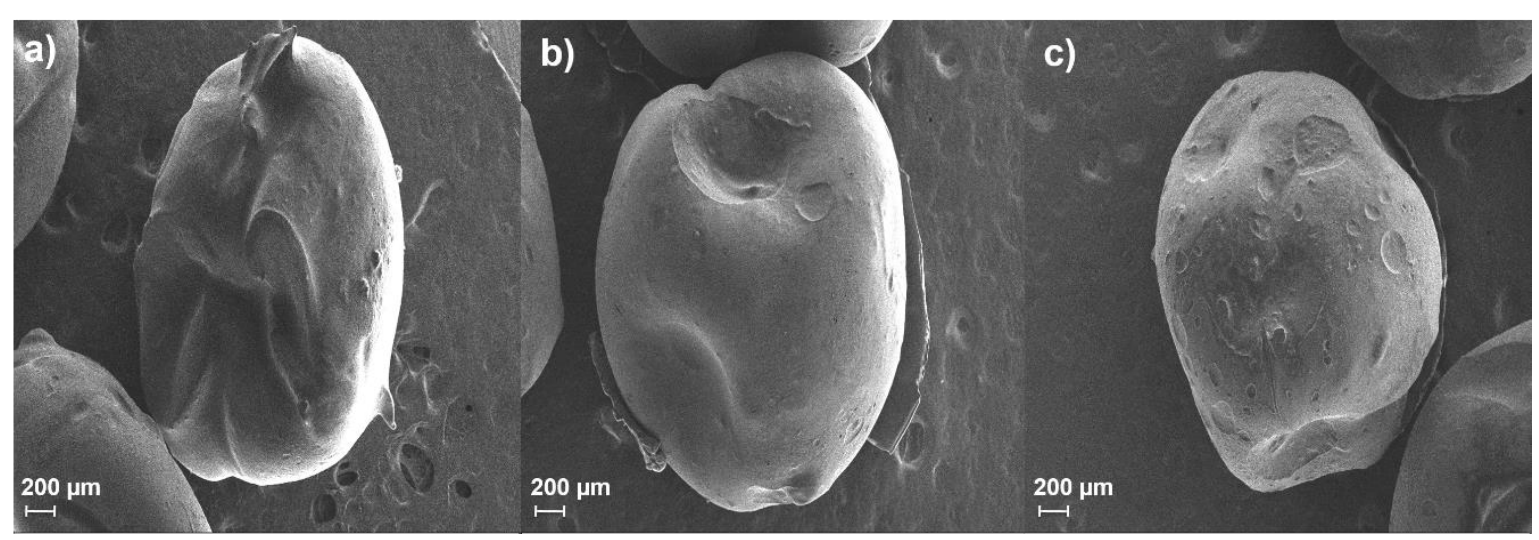

Figure 2. SEM micrographs of (a) neat (Chi-Gel), (b) Chi-Gel/BC1 and (c) Chi-Gel/BC5 biocomposite beads $(31 \mathrm{kX})$.

Table 1. The average elemental composition of biocomposite beads

\begin{tabular}{llll}
\hline Sample & \multicolumn{3}{c}{ Element (at. \%) } \\
\cline { 2 - 4 } & Carbon & Nitrogen & Oxygen \\
\hline Chi-Gel & 52.20 & 18.97 & 28.83 \\
Chi-Gel/BC1 & 76.61 & 5.77 & 17.62 \\
Chi-Gel/BC5 & 61.23 & 10.85 & 27.91 \\
\hline
\end{tabular}

All of the bead samples were also characterized using the Leica M125 stereomicroscope. Figure 3 shows the stereomicrographs of neat chitosan/gelatin and chitosan/gelatin/biochar beads. The average diameter of neat chitosan/gelatin beads was almost $725 \mu \mathrm{m}$ (Figure 3.a). The average diameters of Chi-Gel/BC1 beads and Chi-Gel/BC5 were $726 \mu \mathrm{m}$ and $597 \mu \mathrm{m}$, respectively. The results indicated that the size of Chi-Gel/BC1 beads are nearly the same as that of neat beads, while Chi-Gel/BC5 beads were slightly lower than the other beads. It may be due to the formation of a more rigid network by increased inter and intra polymer matrix-biochar interactions.
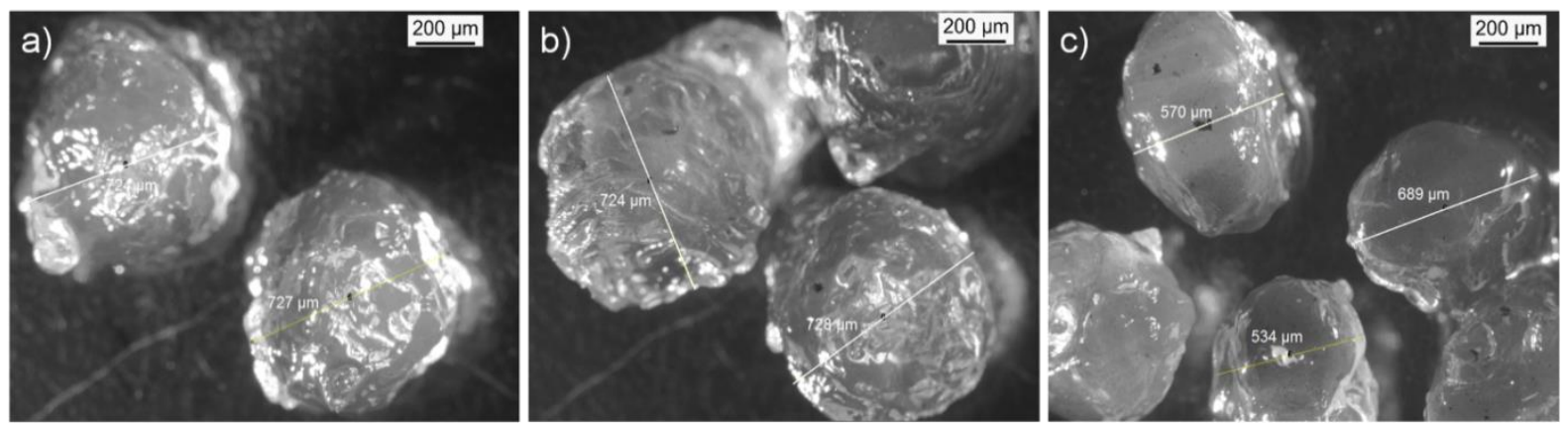

Figure 3. Stereo-micrographs of the (a) neat Chi-Gel, b) Chi-Gel/BC1 and (c) Chi-Gel/BC5 (Zoom: 0.8X). 
The color of composite beads was ranged from yellowish to black (Figure 4). An apparent darkening effect was observed with the incorporation of biochar to the beads. This exhibited the successful incorporation of biochar to the polymer matrix.
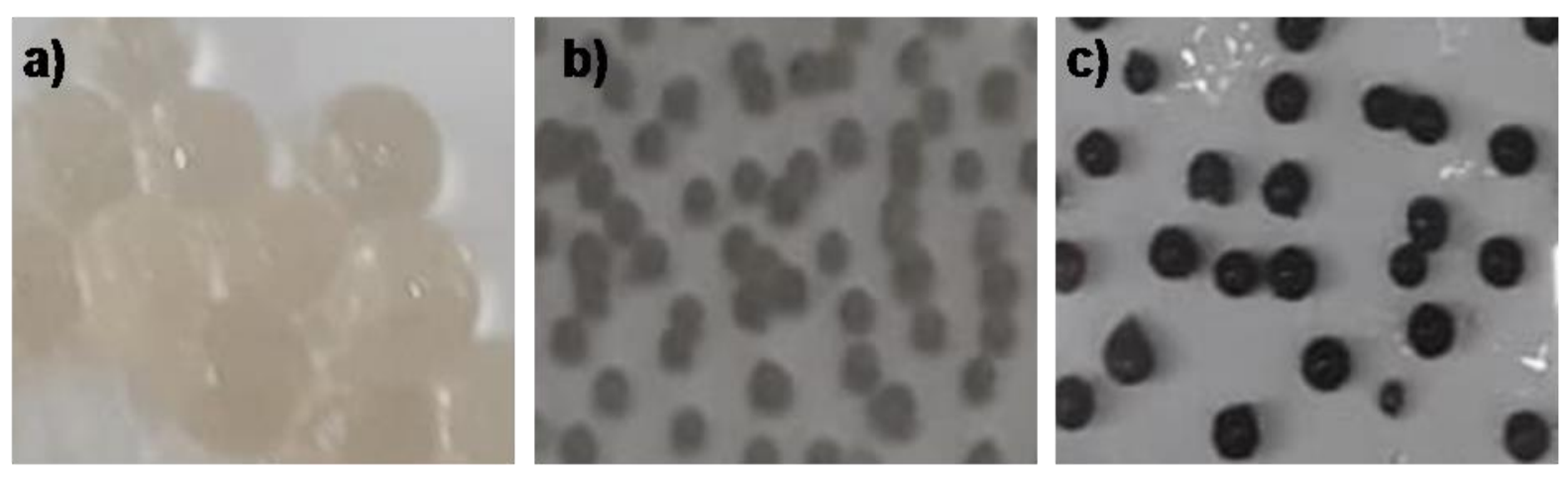

Figure 4. Digital photographs of the biocomposite beads before drying (a) neat (Chi-Gel), (b) Chi-Gel/BC1 and (c) ChiGel/BC5.

\subsection{FT-IR Spectrum}

The chemical composition of the biochar and all bead samples were determined by FT-IR analysis. The FTIR spectrum of the biochar is given in Figure 5. The FTIR spectra of the biochar peak at $1580 \mathrm{~cm}^{-1}$ which corresponded to the $\mathrm{C}=\mathrm{O}$ stretching and aromatic $\mathrm{C}=\mathrm{C}$ vibrations [18]. The peaks at $1444 \mathrm{~cm}^{-1}$ aliphatic $\mathrm{C}-\mathrm{H}$ groups and $\mathrm{C}=\mathrm{C}$ stretching and 882 $\mathrm{cm}^{-1}$ were related to aromatic $\mathrm{C}-\mathrm{H}$ bending, respectively $[19,20]$. The peak at $1080 \mathrm{~cm}^{-1}$ could be related to the C-O stretching [21].

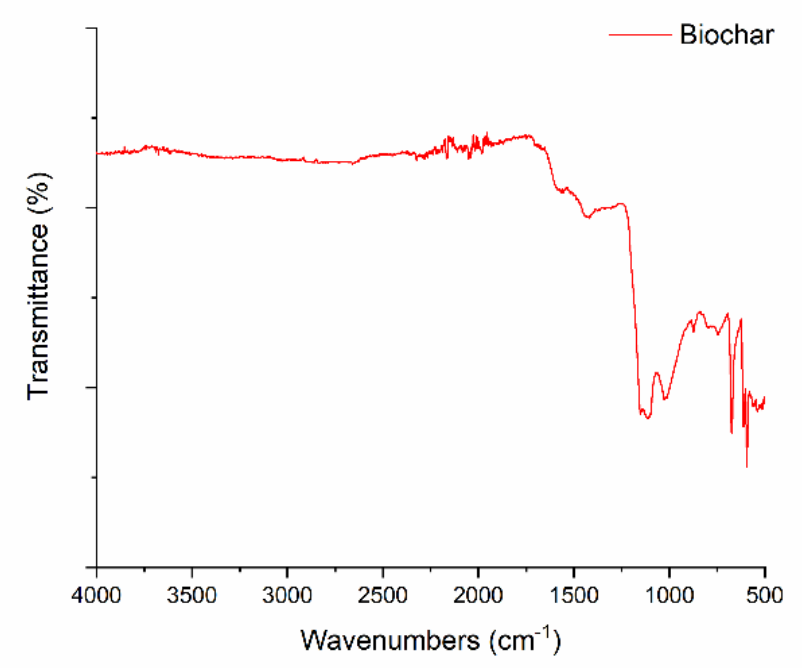

Figure 5. FT-IR spectrum of the biochar. 
In Figure 6, the spectrum of neat chitosan/gelatin bead had a number of characteristic peaks at $3304 \mathrm{~cm}^{-1}(-\mathrm{OH}$ stretching), $2922 \mathrm{~cm}^{-1}$ (C-H stretching), $2853 \mathrm{~cm}^{-1}\left(-\mathrm{CH}_{2}\right.$ stretching) [12,22]. The presence of the peak at $1741 \mathrm{~cm}^{-1}$ carbonyl stretching related to acetate group, $1636 \mathrm{~cm}^{-1}$ related to amide-I, $1543 \mathrm{~cm}^{-1}$ (-NH group-second amine bending), $1456 \mathrm{~cm}^{-1}$ (- $\mathrm{CH}_{2}$ stretching), $1377 \mathrm{~cm}^{-1}\left(\mathrm{CH}_{3}\right.$ group bending) [12,23,24]. Additionally, absorbance peak at $1237 \mathrm{~cm}^{-1}$ might be attributed to $\mathrm{C}-\mathrm{H}$ bending and the slight peaks at $1158 \mathrm{~cm}^{-1}$ and $1094 \mathrm{~cm}^{-1}$ were associated with saccharide units of chitosan stretching and C-O stretching, respectively $[25,26]$. Moreover, the peaks at $950-1106 \mathrm{~cm}^{-1}$ were due to stretching of C-O ether groups of PEG [27].

There were some differences in the composite chitosan/gelatin/biochar bead samples. The absorption peak at $3304 \mathrm{~cm}^{-1}$ shifted to $3295 \mathrm{~cm}^{-1}$, and a shoulder on this peak was occurred due to the second amine. while $2922 \mathrm{~cm}^{-1}$ and $2853 \mathrm{~cm}^{-}$ ${ }^{1}$ shifted slightly $\left(2926 \mathrm{~cm}^{-1}\right.$ and $2923 \mathrm{~cm}^{-1}$, respectively) and $\left(2872 \mathrm{~cm}^{-1}\right.$ and $2854 \mathrm{~cm}^{-1}$, respectively). The amide group peaks (1635 and $\left.1543 \mathrm{~cm}^{-1}\right)$ intensities increased with increasing biochar content.

The peaks of chitosan/gelatin at about $1543 \mathrm{~cm}^{-1}, 1456 \mathrm{~cm}^{-1}$ and $1094 \mathrm{~cm}^{-1}$ shifted to 1538 and $1539 \mathrm{~cm}^{-1}, 1446 \mathrm{~cm}^{-1}$ and $1450 \mathrm{~cm}^{-1}$ and $1065 \mathrm{~cm}^{-1}$ for $1 \%$ and $5 \%$ biochar incorporated samples, respectively. Moreover, the new peaks at $3075 \mathrm{~cm}^{-1}$ and $3078 \mathrm{~cm}^{-1}$ and $1336 \mathrm{~cm}^{-1}$ presented in $1 \%$ and $5 \%$ biochar incorporated samples indicating that physical interaction occurred between chitosan/gelatin and biochar. The peak $3078 \mathrm{~cm}^{-1}$ also indicated the amide group, too. There was also a new peak group about $1000 \mathrm{~cm}^{-1}$ related to cellulosic molecular structure. This peak and amide peak showed that the biochar was composed of protein and cellulosic waste. It can be said that the carbonization of the biochar was not completed, because there were cellulosic and protein peaks on the spectra.

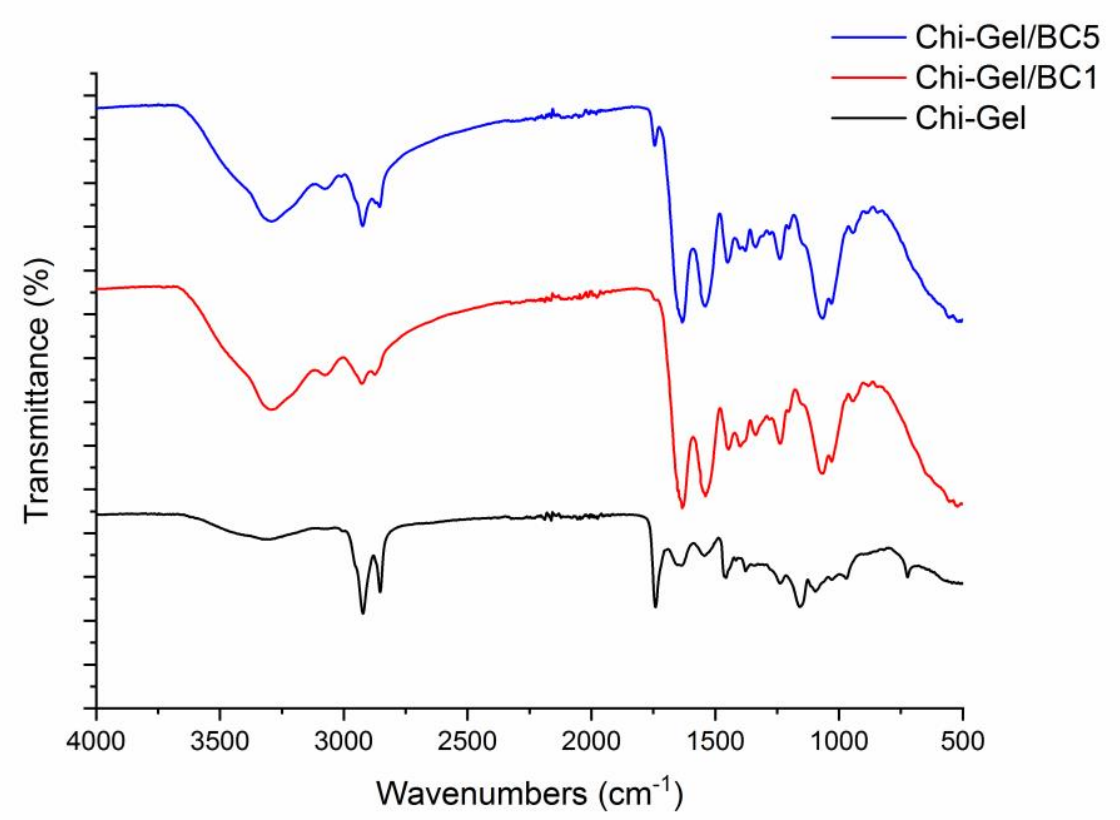

Figure 6. FT-IR spectrum of the neat and biocomposite beads. 


\subsection{Thermogravimetric Analysis}

TGA and DTG thermograms of beads are shown in Figure 7. Thermal behaviour of chitosan/gelatin beads previously recorded by $\mathrm{Wu}$ et al. [12]. Three decomposition stages were observed in the TGA curve of all biocomposite beads. The initial weight loss was slight at the temperature range of $30-150^{\circ} \mathrm{C}[26,28]$ related to the evaporation of water with a weight loss of about $2.56 \%, 2.69 \%$ and $3.17 \%$ for neat Chi-Gel, Chi-Gel/BC1 and Chi-Gel/BC5 beads, respectively. The second stage of degradation occurred at $150^{\circ} \mathrm{C}$ and continued up to $500^{\circ} \mathrm{C}$ [23]. Chi-Gel, Chi-Gel/BC, and ChiGel/BC5 samples had a total weight loss of $77.38 \%, 79.1 \%$, and $74.75 \%$ were related to the decomposition of chitosan main chains and amine groups of gelatin [26]. The third weight loss occurred in the range of $500-675^{\circ} \mathrm{C}[29,30]$. There were $20.05 \%, 18.21 \%$ and $22.07 \%$ weight loss in this stage due to the complex structure of chitosan rings for Chi-Gel, Chi-Gel/BC1 and Chi-Gel/BC5 beads, respectively. The last step of the bead samples was related to the burning of the pyrolysis product which was formed during analysis in the $\mathrm{N}_{2}$ atmosphere. FTIR spectrum of the biochar involves peaks related to the C-O group $\left(1111 \mathrm{~cm}^{-1}\right.$ and $\left.1021 \mathrm{~cm}^{-1}\right)$ and amine group $\left(1592 \mathrm{~cm}^{-1}\right.$ and $\left.1416 \mathrm{~cm}^{-1}\right)$ [18-20]. Before $600^{\circ} \mathrm{C}$, the TGA analysis was carried out in the inert atmosphere, because neat bead undergoes both decomposition and pyrolysis reaction while biochar does not decompose. It is assumed that in this stage less amount of biochar addition increased the heat transfer in the sample, thus Chi-Gel bead was decomposed more than the Chi-Gel/BC1 sample and less pyrolysis product occurred. After $600^{\circ} \mathrm{C}$, both pyrolysis product and biochar were decomposed while the atmosphere was changed from $\mathrm{N}_{2}$ to $\mathrm{O}_{2}$ due to the fact that biochar loaded beads had more weight loss in the last region. In the DTG thermogram, it is clear that the decomposition behaviour of the pyrolysis product and biochar was different due to the shape of the peaks. While biochar decomposition gave a sharp peak, pyrolysis product resulted in a board peak. In the last region $\left(500-675^{\circ} \mathrm{C}\right)$, less amount of weight change in the case of Chi-Gel/BC1 sample resulted from less pyrolosis of the bead due to biochar filler.

TGA curves of biobased beads indicated that there was no phase separation between chitosan and gelatin forms. It can be said that the obtained blends are compatible. This is highly related to the interactions between gelatin and chitosan through hydrogen bonding formation between their functional groups $\left(-\mathrm{OH}\right.$ and $-\mathrm{NH}_{2}$ groups in chitosan and $-\mathrm{NH}_{2}$ groups in gelatin) [28]. A similar study was reported by El-Hefian et al. [28]. The Chi-Gel/BC5 beads showed more thermal stability than the other beads.

a)

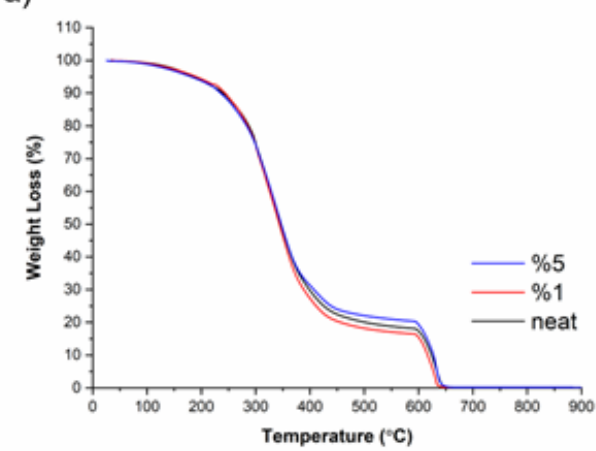

b)

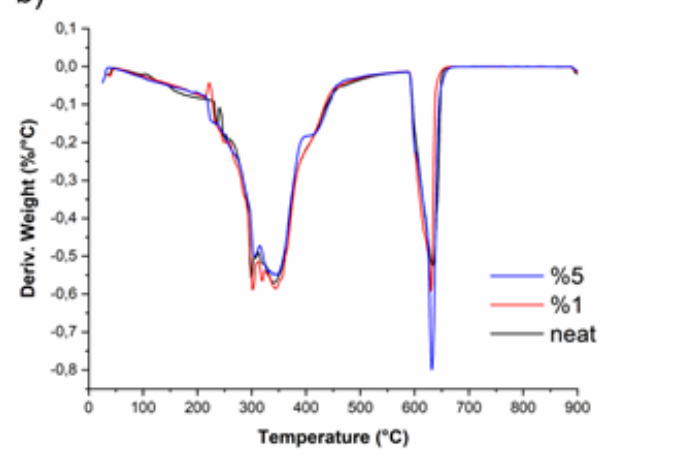

Figure 7. TGA and DTG thermograms of chitosan/gelatin beads. 


\subsection{Water Swelling Behaviour}

Swelling process can be defined as the uptaking of a liquid or gas which leads to an increment in the volume of a connected gel or solid [31]. The swelling ability of hydrogel beads is an important feature to be evaluated that may influence the application of the product ranging from drug delivery systems to adsorbents [32].

The maximum swelling percentages (S\%) of Chi-Gel, Chi-Gel/BC1 and Chi-Gel/BC5 beads were 2361\%, 4671\% and 2092\%, respectively (Figure 8). This reflects that the incorporation of biochar has affected the swelling behaviour of the beads. The swelling ratio of beads were increased with the addition of $1 \%$ biochar to the polymer matrix. However, the $5 \%$ biochar incorporated beads (Chi-Gel/BC5) showed the lowest swelling capacity. The increased biochar content might limit the effectiveness of swelling capacity by acting as the barriers for molecular diffusion of water $[33,34]$.

Furthermore, the sizes of Chi-Gel and Chi-Gel/BC1 beads were a little higher than the Chi-Gel/BC5 sample which might enable penetrating of water through the composite matrix more easily via diffusion and thus favoring the swelling. More cross-linked matrix was obtained with the incorporation of 5\% biochar and finally, the smaller mesh size of polymer network might limit the entrance of water to the polymer structure [32]. Overall, the beads are hydrophilic which shows that the chitosan/gelatin/biochar biocomposite beads can be applied potentially in the tissue engineering field as the hydrophilic nature of the beads will enable the absorption of body fluid, which comprise of mainly water [35]. Digital photographs of the initial and swelled composite beads were given in Figure 9 and Figure 10.

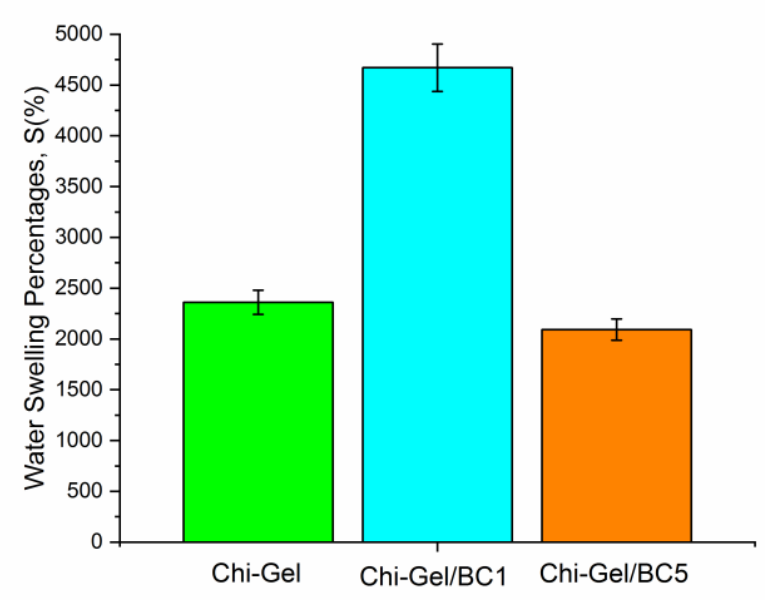

Figure 8. Swelling behaviours of neat Chi-Gel, Chi-Gel/BC1 and Chi-Gel/BC5 beads. 


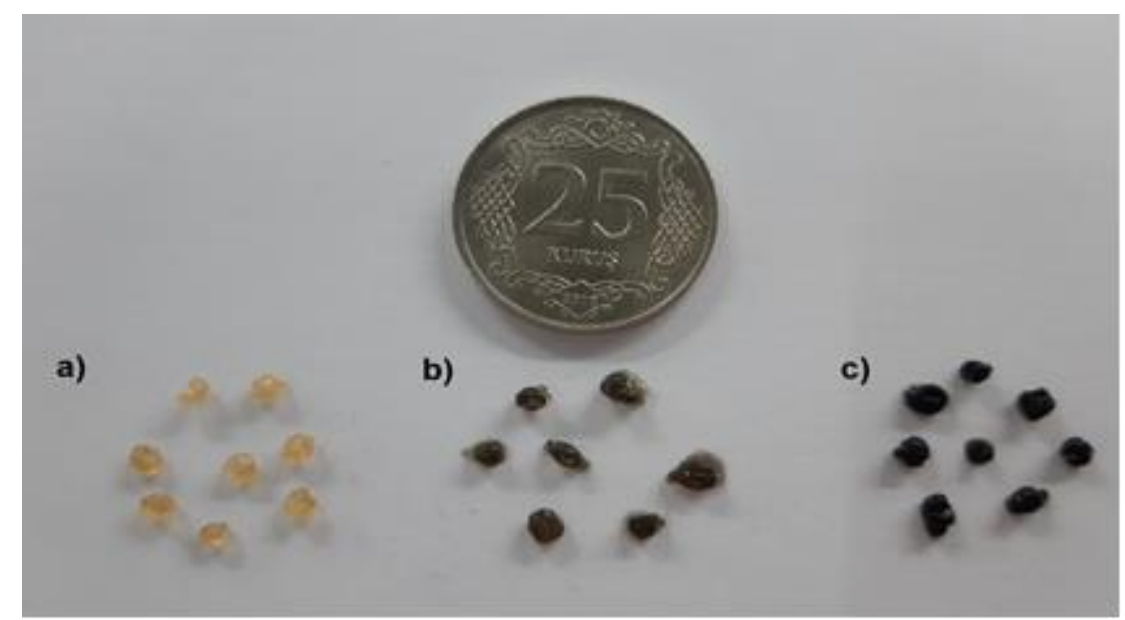

Figure 9. Digital photographs of the biocomposite beads before swelling (a) neat (Chi-Gel), (b) Chi-Gel/BC1 and (c) Chi-Gel/BC5.
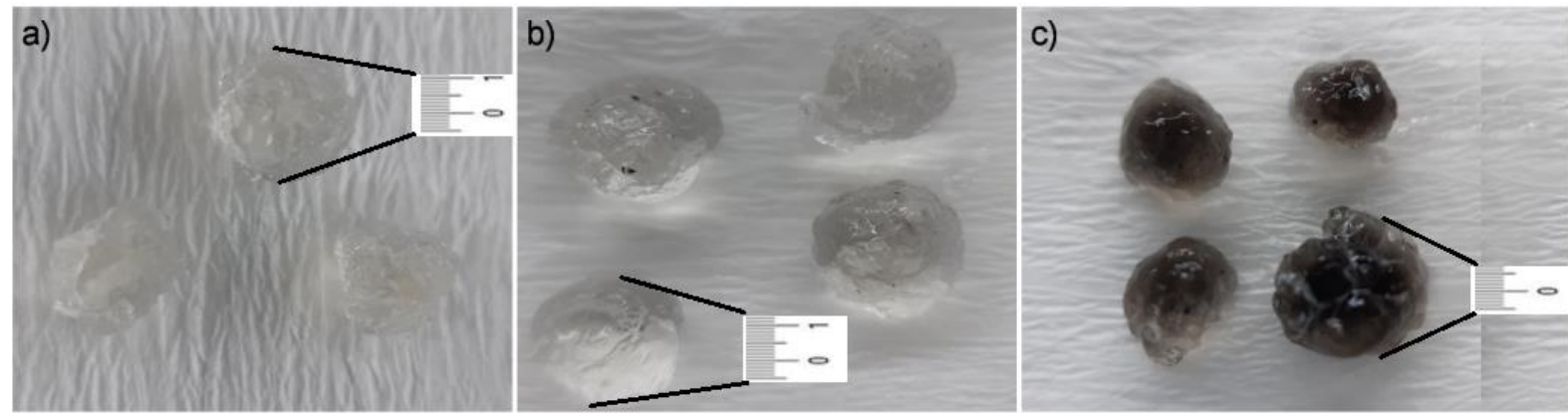

Figure 10. Digital photographs of the biocomposite beads after swelling for 6-hour (a) neat (Chi-Gel), (b) Chi-Gel/BC1 and (c) Chi-Gel/BC5.

\section{Conclusion}

Chitosan/gelatin/biochar beads were prepared using the emulsion crosslinking method in the presence of PEG. The biochar was efficiently incorporated into the polymer matrix. The properties of the beads were greatly affected by biochar addition. The morphology of the neat beads became smoother with the incorporation of the biochar. The thermal stability of chitosan-gelatin beads was enhanced with the addition of $5 \%$ biochar. The increment of biochar content from $1 \%$ to $5 \%$ in the composite bead made the bead approximately $50 \%$ less susceptible to water. In general, carbon filler loaded chitosan and gelatin-based beads were evaluated as drug delivery systems and adsorbents to remove heavy metal or dye from aqueous solutions. The biochar incorporated beads will be potential eco-friendly candidates for adsorption and biomedical applications which should be demonstrated with further studies.

\section{Acknowledgement}

The authors of this study would like to express their appreciations to Murat EROĞLU and İbrahim ŞEN (Central Research Laboratory, Bursa Technical University) for their help in SEM and TGA analysis. 


\section{Funding}

This study did not receive any specific grant from funding agencies in the public, commercial, or not-for-profit sectors.

\section{References}

[1] Mohammad J. Zohuriaan-Mehr, Kourosh Kabiri (2008). Superabsorbent Polymer Materials: A Review, Iranian Polymer Journal, 17(6):451-477.

[2] Cheng, B., Pei, B., Wang Z. and Hu, Q. (2017). Advances in chitosan-based superabsorbent hydrogels, Royal Society of Chemistry Advances, 7:42036-42046.

[3] Behera, S. and Mahanwar, P. A. (2019). Superabsorbent polymers in agriculture and other applications: a review. Polymer-Plastics Technology and Materials, 59(4):1-16.

[4] Ahmed, E. M. (2015) Hydrogel: Preparation, characterization, and applications: A review. Journal of Advanced Research, 6:105-121.

[5] Qu, B. and Luo, Y. (2020). Chitosan-based hydrogel beads: Preparations, modifications and applications in food and agriculture sectors - A review. International Journal of Biological Macromolecules, 152:437-448.

[6] Pradeep-Kumar, S., Gowda D. V. and Vikas, J. (2020). Recent Development in Sustained Release Beads. International Journal of Research Pharmaceutical Science, 11(1):891-898.

[7] Bahram, M., Mohseni, N. and Moghtader, M. (2016). Emerging Concepts in Analysis and Applications of Hydrogels, Edited by Sutapa Biswas Majee, IntechOpen, London, UK. pp. 9-38. ISBN: 978-953-51-2510-5.

[8] Trikkaliotis, D. G. Christoforidis, A. K. Mitropoulos, A. C. and Kyzas, G. Z. (2020). Adsorption of copper ions onto chitosan/poly(vinyl alcohol) beads functionalized with poly(ethylene glycol). Carbonhydrate Polymers, 234:115890.

[9] Ngah, W. S. W., Kamari, A., Koay, Y. J. (2004). Equilibrium and kinetics studies of adsorption of copper (II)on chitosan and chitosan/PVA beads. International Journal of Biological Macromolecules, 34:155-161.

[10] Yuvaraja, G., Pathak, J. L., Weijiang, Z., Yaping, Z. and Jiao, X. (2017). Antibacterial and wound healing properties of chitosan/poly(vinyl alcohol)/zinc oxide beads (CS/PVA/ZnO). International Journal of Biological Macromolecules, 103, 234-241.

[11] Li, K., Wang, Y., Miao, Z., Xu, D., Tang, Y. and Feng, M. (2004). Chitosan/gelatin composite microcarrier for hepatocyte culture. Biotechnology Letters, 26:879-883. [12] ArcGIS. https://www.arcgis.com/index.html, Accessed: 02/04/2020.

[12] Wu, M., Chen, W., Mao, Q., Bai, Y. and Ma, H. (2019). Facile synthesis of chitosan/gelatin filled with graphene bead adsorbent for orange II removal. Chemical Engineering Research and Design, 144:35-46.

[13] Zeinali, A., Sirousazar, M., Hosseini, Z., Kheir, D. and Kheir, F. (2020). Gelatin/Montmorillonite and Gelatin/Polyvinyl Alcohol/Montmorillonite Bionanocomposite Hydrogels: Microstructural, Swelling and Drying Properties. Journal of Macromolecular Science, Part B, https://doi.org/10.1080/00222348.2019.1709714. 
[14] Saber-Samandari, S., Saber-Samandari, S., Yekta, H. and Mohseni, M. (2016). Adsorption of anionic and cationic dyes from aqueous solution using gelatinbased magnetic nanocomposite beads comprising carboxylic acid functionalized carbon nanotube. Chemical Engineering Journal, 308:1133-1144.

[15] Zhang, H., Chang, Q., Han, J., Gao, S., Wu, Z., Hu, J., Yang, Y., Wei, Z., Zhang, De. and Peng, Z. (2019). A facile syntheses of two engineered poly(vinyl alcohol) macroporous hydrogel beads for the application of $\mathrm{Cu}(\mathrm{II})$ and $\mathrm{Pb}(\mathrm{II})$ removal: batch and fixed bed column. Materials Research Express, 6(9):095315.

[16] Terzioğlu, P., Parın, F. N. (2020). Biochar Reinforced Polyvinyl Alcohol /Corn Starch Biocomposites. Süleyman Demirel Üniversitesi, Fen Bilimleri Enstitüsü Dergisi, 24(1):35-42

[17] Dewage, N. B., Fowler, R. E., Pittman, C. U., Mohan, D. and Mlsna, T. (2018). Lead (Pb2+) sorptive removal using chitosan modified biochar: batch and fixed-bed studies. RSC Adv., 8, 25368.

[18] Smidt, E., and Meissl, K. (2007). The applicability of Fourier transform infrared (FT-IR) spectroscopy in waste management. Waste Manag., 27(2), 268-276

[19] Wu, M., Feng Q., Sun X., Wang H., Gielen G. (2015). Rice (Oryza sativa L) plantation affects the stability of biochar in paddy soil. Scientific Reports., 5:10001, 1-10.

[20] Tatzber, M., Stemmer, M., Spiegel, H., Katzlberger, C., Haberhauer, G., Mentler, A., and Gerzabek, M. H. (2007). FTIR-spectroscopic characterization of humic acids and humin fractions obtained by advanced $\mathrm{NaOH}$, Na4P2O7, and Na2CO3 extraction procedures. J. Plant Nutr. Soil Sci. 170(4), 522-529.

[21] Schwanninger, M., Rodrigues, J. C., Pereira, H., and Hinterstoisser, B. (2004). Effects of short-time vibratory ball milling on the shape of FT-IR spectra of wood and cellulose. Vib. Spectrosc. 36(1), 23-40.

[22] Zheng, X. F., Lian Q., Yang, H. and Wang X. (2016). Surface Molecularly Imprinted Polymer of Chitosan Grafted Poly(methyl methacrylate) for 5-Fluorouracil and Controlled Release. Scientific Reports, 6:21409.

[23] Kumar, S. and Koh, J. (2012). Physiochemical, Optical and Biological Activity of Chitosan-Chromone Derivative for Biomedical Applications. International Journal of Molecular Science, 13:6102-6116.

[24] Yasmeen, S., Kabiraz, M. K., Saha, B., Qadir, R., Gafur, A. and Masum, S. (2016). Chromium (VI) Ions Removal from Tannery Effluent using Chitosan-Microcrystalline Cellulose Composite as Adsorbent. International Research Journal of Pure \& Applied Chemistry, 10(4):1-14.

[25] Cui, L., Xiong, Z., Guo, Y., Liu, Y., Zhao, J., Zhang, C. and Zhu, P. (2015). Fabrication of interpenetrating polymer network chitosan/gelatinporous materials and study on dye adsorption properties. Carbohydrate Polymers, 132:330-337.

[26] Nady, N. and Kandil, S. H. (2018). Novel Blend for Producing Porous Chitosan-Based Films Suitable for Biomedical Applications. Membranes, 8:2-18.

[27] Mohamed, R.R., Seoudi, R.S. Sabaa, M.W. (2015). Synthesis and Characterization of Crosslinked Polyethylene Glycol/Carboxymethyl Chitosan Hydrogels. Advances in Polymer Technology, 34(1), 21479.

[28] El-Hefian, E. A., Nasef, M. M. and Yahaya, A. H. (2012). Preparation and Characterization of Chitosan/Agar Blended Films: Part 2. Thermal, Mechanical, and Surface Properties. E-Journal of Chemistry, 9(2):510-516.

[29] Wu, Z. C., Wang, Z. Z., Liu, J., Yin, J. H. and Kuang, S. P. (2016). Removal of Cu(II) ions from aqueous water by l-arginine modifying magnetic chitosan. Colloids and Surfaces A: Physicochemical and Engineering Aspects, 499:141-149. 
[30] Chen, I. H., Chien, C. M., Wang, C. T., Huang, C. L., Wang, C. K. and Kuo, Y. R. (2018). Development for Wound Dressing Based on Blended Chitosan and Gelatin Hydrogels. Key Engineering Materials, 765:119-123.

[31] Sienkiewicz, A., Krasucka, P., Charmas, B., Stefaniak, W., Goworek, J. (2017). Swelling effects in cross-linked polymers by thermogravimetry. J Therm Anal Calorim, 130:85-93. [20] Senturk, I.F.(2017). A prescient recovery approach for disjoint msns. In 2017 IEEE International Conference on Communications (ICC),

[32] Carbinatto, F. M., Castro, A. D., Evangelista, R. C., Cury, B. S. F. (2014). Insights into the swelling process and drug release mechanisms from cross-linked pectin/high amylose starch matrices, Asian Journal of Pharmaceutical Sciences, 9(1), 27-34.

[33] Yu, O. Y., Raichle, B. and Sink, S. (2013). Impact of biochar on the water holding capacity of loamy sand soil, International Journal of Energy and Environmental Engineering, 4:44.

[34] Wan, Y. Z., Wang, Y. L., Yao, K. D. and Cheng, G. X. (2000). Carbon fiber-reinforced gelatin composites. II. Swelling behaviour. Journal of Applied Polymer Science, 75:994-998

[35] Sharma, C., Dinda, A. K., Potdar, P. D. Chou, C. F. and Mishra, N. C. (2016). Fabrication and characterization of novel nano-biocomposite scaffold of chitosan-gelatin-alginate-hydroxyapatite for bone tissue engineering. Materials Science and Engineering C, 64:416-427. 